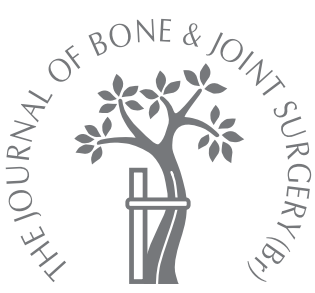

N. Giotakis, S. K. Panchani, B. Narayan, J. J. Larkin, S. Al Maskari, S. Nayagam

From the Royal Liverpool University Hospital, Liverpool, England

\title{
Segmental fractures of the tibia treated by circular external fixation
}

We have carried out a retrospective review of 20 patients with segmental fractures of the tibia who had been treated by circular external fixation. We describe the heterogeneity of these fractures, their association with multiple injuries and the need for multilevel stability with the least compromise of the biology of the fracture segments. The assessment of outcome included union, complications, the measurement of the functional IOWA knee and ankle scores and the general health status (Short-form 36).

The mean time to union was 21.7 weeks (12.8 to 31 ), with no difference being observed between proximal and distal levels of fracture. Complications were encountered in four patients. Two had nonunion at the distal level, one a wire-related infection which required further surgery and another shortening of $15 \mathrm{~mm}$ with $8^{\circ}$ of valgus which was clinically insignificant. The functional scores for the knee and ankle were good to excellent, but the physical component score of the short-form 36 was lower than the population norm. This may be explained by the presence of multiple injuries affecting the overall score.

Segmental fractures of the tibia are uncommon, but present difficulties in management because of the wide zone of injury, potentially reduced viability of the bone and problems with stabilisation. These high-energy fractures are likely to be associated with injuries elsewhere. Various methods of treatment have been proposed including casting and functional bracing, internal fixation by plates and screws, intramedullary nailing and external fixation.

External fixation has the potential to provide multilevel stabilisation of the fracture with minimal disruption of the soft-tissue envelope. Circular external fixation gives multiplanar control which is absent from monolateral designs. We report a retrospective assessment of a consecutive series of patients with segmental tibial fractures who had been treated by circular external fixation. ${ }^{1-3}$

\section{Patients and Methods}

We treated 20 adult patients $(15$ men, five women) with segmental tibial injuries between January 2000 and February 2006. Their mean age was 47.2 years ( 25 to 79 ). In 17 , the fracture had been sustained in a road-traffic accident and in three by a fall. In seven patients the fracture was a solitary injury, in five it was associated with one other injury and in the remaining eight it was part of multiple injuries. The mean injury severity score (ISS) was 21.3 (9.0 to 48.0).
All the fractures were classified as type $42 \mathrm{C}$ using the $\mathrm{AO} / \mathrm{OTA}^{4}$ classification and open injuries were graded by the Gustilo and Anderson classification. ${ }^{5}$ There were seven open fractures, four type $3 \mathrm{~B}$ and three type $3 \mathrm{~A}$ (Table I).

Of the 20 patients, 11 were admitted directly to the unit and the other nine were tertiary referrals. Initial stabilisation by a spanning external fixator was used in seven fractures (four open and three closed). One of the patients with a closed fracture developed a compartment syndrome and had fasciotomies when the fixator was being applied. Two open fractures (type 3A) were stabilised by a circular fixator after debridement and wound closure at primary surgery. For type-3B open fractures, temporary cover was given with either gentamicin bead pouches or vacuum-assisted closure dressings. One fracture was stabilised initially by an intramedullary nail, but this failed to control alignment and he was transferred for a revision procedure (Fig. 1). The remaining ten patients had their fractures supported provisionally in plaster-of-Paris splints or traction.

In all the patients the definitive treatment was circular external fixation. The mean time of application was 14.5 days (1 to 34) after injury, with any delay being attributed to the treatment of other injuries, the need for plastic surgery in type-3B fractures or postponement to allow soft-tissue conditions to improve 
Table I. Details of the 20 patients and results after external fixation

\begin{tabular}{|c|c|c|c|c|c|c|c|c|c|c|c|c|c|c|c|}
\hline Case & $\begin{array}{l}\text { Age } \\
\text { (yrs) }\end{array}$ & $\begin{array}{l}\text { AO/OTA }^{*} \\
\text { classification }\end{array}$ & Gender & $\begin{array}{l}\text { Closed/ } \\
\text { ropen }\end{array}$ & ISS $^{\dagger}$ & $\begin{array}{l}\text { Multi } \\
\text { segmental }\end{array}$ & $\begin{array}{l}\text { Sec. proc infected } \\
\text { wire site }\end{array}$ & $\begin{array}{l}\text { Time to } \\
\text { frame (days) }\end{array}$ & $\begin{array}{l}\text { Proximal } \\
\text { gap }(\mathrm{mm})\end{array}$ & $\begin{array}{l}\text { Distal } \\
\text { gap } \\
(\mathrm{mm})\end{array}$ & $\begin{array}{l}\text { Proximal } \\
\text { healing time } \\
\text { (wks) }\end{array}$ & $\begin{array}{l}\text { Distal } \\
\text { healing } \\
\text { time (wks) }\end{array}$ & $\begin{array}{l}\text { Fixed } \\
\text { time } \\
\text { (wks) }\end{array}$ & $\begin{array}{l}\text { Distance } \\
\text { from knee } \\
\text { (cm) }\end{array}$ & $\begin{array}{l}\text { Distance } \\
\text { from } \\
\text { ankle }(\mathrm{cm})\end{array}$ \\
\hline 1 & 29 & $42 / \mathrm{C} 3$ & $\mathrm{M}$ & Closed & 16 & Yes & & 4 & 6 & 2 & 28 & 28 & 31 & 6.0 & 8.3 \\
\hline 2 & 27 & $42 / \mathrm{C} 3$ & $M$ & Closed & 48 & Yes & & 22 & 7 & 3 & 31 & 25 & 29 & 2.1 & 2.4 \\
\hline 3 & 53 & $42 / C 3$ & M & Closed & 25 & No & & 13 & 2 & 6 & 15 & 22 & 22 & 4.6 & 5.4 \\
\hline 4 & 52 & $42 / \mathrm{C} 2$ & M & $\begin{array}{l}\text { Open } \\
3 \mathrm{~B}\end{array}$ & 25 & No & & 29 & 3 & 2 & 13 & 13 & 13 & 2.2 & 13.2 \\
\hline 5 & 55 & $42 / \mathrm{C} 3$ & M & Closed & 16 & No & & 21 & 2 & 2 & 19 & 19 & 19 & 6.2 & 13.3 \\
\hline 6 & 56 & $42 / \mathrm{C} 3$ & M & $\begin{array}{l}\text { Open } \\
3 \mathrm{~A}\end{array}$ & 16 & Yes & & 5 & 2 & 5 & 23 & 23 & 24 & 6.0 & 15.2 \\
\hline 7 & 30 & $42 / \mathrm{C} 2$ & M & Closed & 20 & No & & 7 & 2 & 1 & 13 & 13 & 15 & 8.0 & 6.3 \\
\hline 8 & 55 & $42 / \mathrm{C} 3$ & M & $\begin{array}{l}\text { Open } \\
3 \mathrm{~B}\end{array}$ & 20 & Yes & $\begin{array}{l}\text { Compartment } \\
\text { syndrome }\end{array}$ & 34 & 5 & 3 & 30 & 26 & 21 & 5.7 & 8.1 \\
\hline 9 & 34 & $42 / \mathrm{C} 3$ & M & Closed & 25 & No & & 19 & 3 & 4 & 24 & 24 & 30 & 2.8 & 12.0 \\
\hline 10 & 64 & $42 / \mathrm{C} 3$ & $M$ & Closed & 25 & No & & 13 & 3 & 2 & 23 & 23 & 25 & 4.8 & 21.0 \\
\hline 11 & 52 & $42 / \mathrm{C} 3$ & M & $\begin{array}{l}\text { Open } \\
3 A\end{array}$ & 25 & Yes & & 1 & 12 & 10 & 19 & 24 & 30 & 4.3 & 9.0 \\
\hline 12 & 52 & $42 / C 2$ & $M$ & $\begin{array}{l}\text { Open } \\
3 A\end{array}$ & 25 & No & & 1 & 3 & 2 & 31 & 31 & 35 & 3.1 & 13.6 \\
\hline 13 & 64 & $42 / \mathrm{C} 2$ & M & Closed & 16 & No & $\begin{array}{l}\text { Nonunion } \\
\text { (Sheffield) }\end{array}$ & 8 & 2 & 2 & 36 & 90 & 93 & 15.0 & 11.2 \\
\hline 14 & 25 & $42 / \mathrm{C} 3$ & $M$ & $\begin{array}{l}\text { Open } \\
\text { 3B }\end{array}$ & 25 & No & $\begin{array}{l}\text { Nonunion } \\
\text { (Ilizarov) }\end{array}$ & 21 & 11 & 0 & 12 & 81 & 21 & 4.5 & 10.0 \\
\hline 15 & 31 & $42 / C 2$ & $M$ & Closed & 16 & No & & 5 & 3 & 1 & 24 & 24 & 27 & 15.3 & 11.0 \\
\hline 16 & 79 & $42 / C 2$ & $\mathrm{~F}$ & Closed & 16 & No & & 18 & 0 & 10 & 12 & 12 & 15 & 7.8 & 15.5 \\
\hline 17 & 39 & $42 / \mathrm{C} 3$ & $\mathrm{~F}$ & $\begin{array}{l}\text { Open } \\
\text { 3B }\end{array}$ & 16 & Yes & & 31 & 4 & 1 & 30 & 30 & 20 & 3.0 & 6.0 \\
\hline 18 & 49 & $42 / C 3$ & $F$ & Closed & 25 & No & & 28 & 8 & 2 & 11 & 15 & 15 & 5.6 & 16.0 \\
\hline 19 & 38 & $42 / \mathrm{C} 3$ & $\mathrm{~F}$ & Closed & 16 & No & & 5 & 8 & 6 & 17 & 23 & 28 & 4.7 & 6.4 \\
\hline 20 & 48 & $42 / C 2$ & $\mathrm{~F}$ & Closed & 9 & No & & 5 & 3 & 1 & 18 & 26 & 31 & 15.0 & 4.8 \\
\hline
\end{tabular}

* AO/OTA, Orthopaedic Trauma Association classification

† ISS, injury severity score

(Table I). The types of circular external fixator used were the Ilizarov (Smith and Nephew, Memphis, Tennesse), the Sheffield Ring Fixator (Orthofix, Verona, Italy) and the Taylor Spatial Frame (Smith and Nephew). Although three different types of fixator were used according to the preference of the surgeon, every application followed three principles. First, each fracture segment was stabilised by two levels of fixation, either two rings or, if the segment was short, a single ring with 'drop wires' on either side. Secondly, wires alone were used in the Ilizarov fixators in order to reproduce the beam-loading characteristics and isotropic behaviour of the system. These characteristics reduced shear by self-stiffening behaviour and were independent of the direction of force applied to the fracture. ${ }^{6}$ Thirdly, with the Sheffield Ring and Taylor Spatial fixators, combinations of wires and half-pins were used according to earlier work in order to simulate the beam-loading characteristics of an all-wire system. ${ }^{7}$

The quality of the reduction of the fracture was determined on standard post-operative orthogonal radiographs. Attempts to improve contact and alignment were usually undertaken in a dedicated limb reconstruction outpatient clinic by the application of hinges and motors to effect a gradual correction. In some cases, a large gap was present because of bone loss after debridement. Bone grafts were not used when the bone loss was less than one-third of the circumference of the tibial segment. The care of pin sites was according to the recommendations of the Russian Ilizarov Scientific Centre for Restorative Traumatology and Orthopaedics (RISC RTO) ${ }^{8}$ in Kurgan, Siberia. This involves a weekly regimen of cleaning with alcoholic chlorhexidine and occlusion of the pin site by a bulky dressing. This protocol has previously been found to give a lower incidence of infection than daily cleaning with normal saline. ${ }^{8}$

Partial weight-bearing was allowed and increased as confidence and ability improved. Because of other injuries some patients were unable to manage weight-bearing with crutches for several weeks. After discharge from hospital the patients were followed at regular three- to five-weekly review and at physiotherapy sessions.

Union was determined clinically and radiologically. Clinical union was achieved when the patient could bear weight fully through the affected leg without supporting aids. Radiologically, callus bridging at the site of the fracture was assessed although, in well-reduced fractures with a barely visible gap, blurring of a fracture line was all that was visible in some cases. Staged extraction of wires or half-pins from intermediate ring levels of the fixator allowed increasing transfer of weight through the limb and not the fixator. When radiological and clinical union had been achieved removal of the fixator was carried out under Entonox in the clinic or under general anaesthesia. Five patients were sup- 


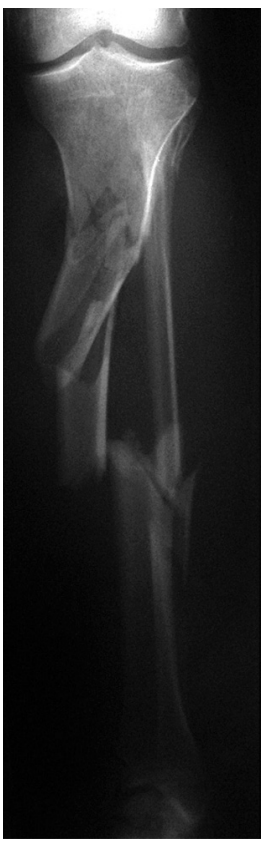

Fig. 1a

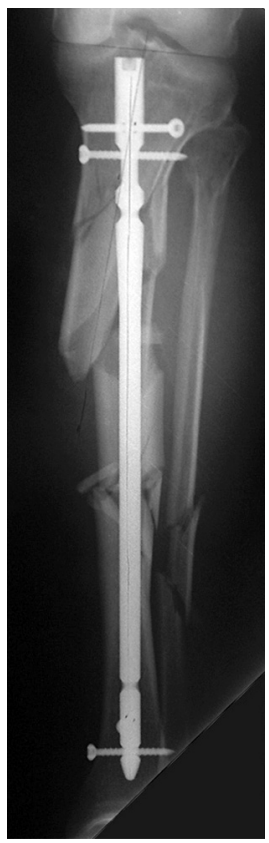

Fig. 1b

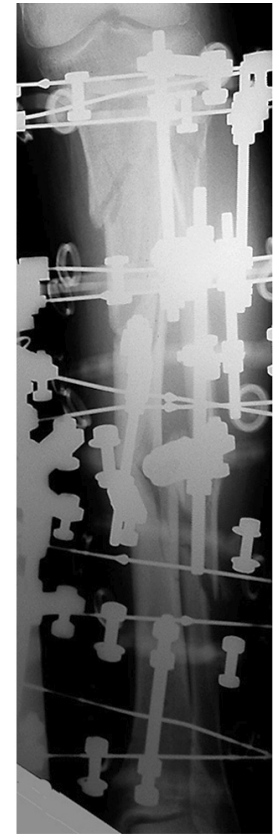

Fig. 1c

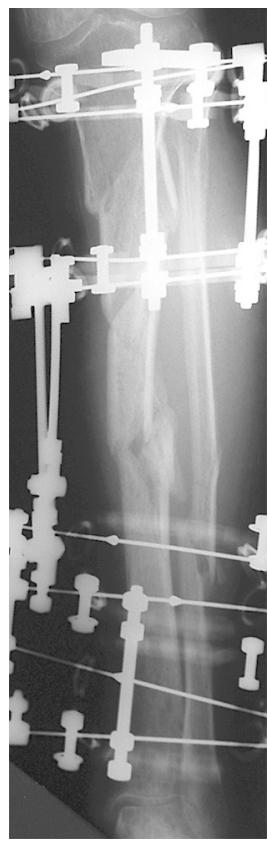

Fig. 1d

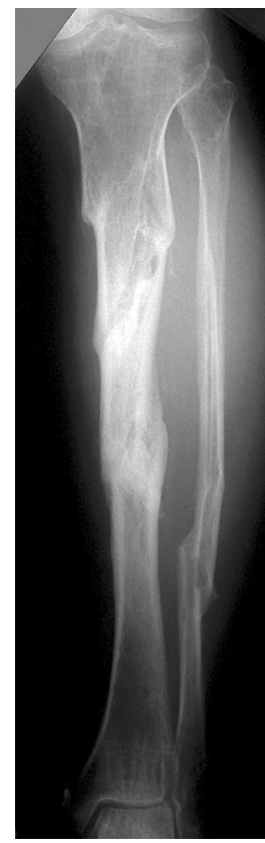

Fig. 1e

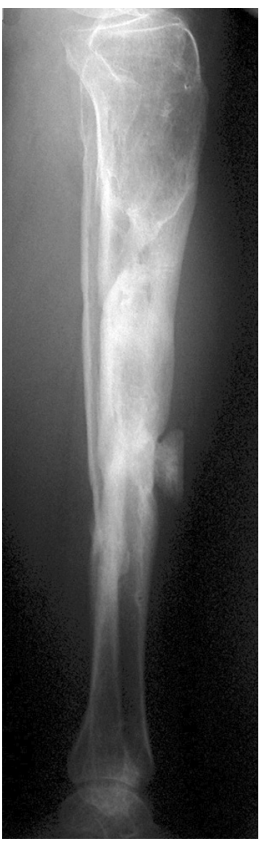

Fig. $1 f$

Radiographs of patient 6 showing a) the fracture, b) the initial treatment by intramedullary nailing, c) removal of the nail and conversion to a circular frame, d) the appearance at time of healing and e) and f) 6 months after removal of the frame.

ported by casts or functional braces for a mean of six weeks (3 to 11) because of concerns over the patients ability to comply with weight bearing restrictions following removal of the frame.

Collection of data was by review of case notes, radiographs and recent clinical examination. Four outcome measures were assessed: healing of the fracture, complications of treatment, functional recovery and general health status. Healing was represented as time to union. The influence of the characteristics of the patient and the fracture on union was investigated by multiple regression analysis. The patient's age, the ISS, the nature of the injury (open or closed) and the size of the fracture gap (after any postsurgical corrections through the fixator) at the different fracture levels were also considered. Complications of treatment were assessed by the type and number of unscheduled operations and any malalignment after union. Pin-site infection, which is common with the use of external fixators, was recorded, but listed as a complication only if secondary intervention other than the administration of antibiotics was needed.

The functional recovery was recorded at the final review using the IOWA knee and ankle score ${ }^{9}$ and the generalhealth status was measured by the short-form (SF-)36 version 2 questionnaire. ${ }^{10}$ The IOWA knee and ankle score is a questionnaire and clinical-examination-based evaluation of the function of the knee and ankle. The knee score is a fivecategory measurement, which includes activities of daily living, freedom from pain, gait, aid dependence, deformity and range of movement. The ankle score is a four-category measurement of function, freedom from pain, gait and range of movement. The SF-36 is a 36 -item questionnaire which provides a general measurement of health that can be compared with population norms. It has eight categories: physical functioning, role physical, bodily pain, general health, vitality, social functioning, role emotional and mental health. These can be grouped into two categories to represent measures of physical and mental health.

Statistical analysis. Multiple regression analysis was used to assess the relationships between the functional and general health scores and the characteristics of the fracture. For continuous variables, we used linear regression methods. With dichotomous variables, we used the technique of 'dummy variables' in linear regression, which produced an analysis of covariance. The Wilcoxon rank-sum test was used to determine if the time to fracture healing was related to whether the fracture was open or closed. A paired $t$-test compared the measured residual gap at the proximal and distal levels of the fracture. The software used in the analysis was Stata 10 (Statacorp, Bryan, Texas). A p-value of $\leq 0.05$ was considered to be statistically significant.

\section{Results}

The case notes and radiographs were available for all the patients. Clinical review with functional and general-health assessment, was achieved in 17 and the SF-36 questionnaire was available in 18 . The mean follow-up was for 5.9 years (1.8 to 8.9 ).

Fracture healing. Union was achieved at a mean of 21.7 weeks (12.8 to 31). Two fractures failed to unite at a single 
level. Two non-compliant patients were lost to follow-up before returning many months later with healed fractures and requesting removal of the fixator. When comparing times to union there was no difference between open and closed fractures (Wilcoxon rank-sum test, $\mathrm{p}=0.49$ ). After application of the fixator and reduction, the largest visible fracture gap on either of the two radiological views was measured to the nearest millimetre. The mean gap size was $4.45 \mathrm{~mm}$ (0 to 12) at the most proximal level and $3.25 \mathrm{~mm}$ (1 to 10 ) at the most distal. Comparison of the two measured gaps showed no significant difference (paired $t$-test, $\mathrm{p}=0.35$; mean difference $0.87 \mathrm{~mm}, 95 \%$ confidence interval -1.08 to +2.83 ). Multiple regression analysis showed no significant relationship between the time to union and the residual fracture gap, the nature of the fracture (open or closed), age or the ISS ( $\mathrm{p}=0.89$ ).

Complications. Two patients had nonunion at the distal level which was managed successfully by further circular external fixation in one and open autogenous bone grafting and revision of external fixation in the other. One patient developed osteomyelitis at a pin-site requiring exchange of the wire after debridement. Malalignment was identified in three patients measuring $5^{\circ}$ and $8^{\circ}$ valgus and $5^{\circ}$ of procurvatum, respectively. The patient with $8^{\circ}$ of valgus had $15 \mathrm{~mm}$ of shortening. None of the measured deformities was clinically visible. We were not able to determine the effect of any malalignment on the mechanical axis of the limb since the taking of full-length standing radiographs was not a routine procedure.

Functional recovery. The IOWA knee and ankle scores are grouped into excellent (90 to 100), good (80 to 89) and fair (70 to 79) categories. Of the 17 patients who had functional scoring (Table II) most achieved good or excellent scores. Multiple regression analysis showed no significant relationship between the knee and ankle scores and the same variables as described for time to union (IOWA knee, $\mathrm{p}=0.99$; IOWA ankle, $\mathrm{p}=0.73$ ).

The SF-36 raw scores were converted to norm-based scores based on United Kingdom population data from $1998^{10}$ (Fig. 2). This allowed direct comparison of each of the eight-item scales and the physical and mental component summaries with the normal population. Each item and component summary had a mean of 50 and an SD of 10 for the United Kingdom. Therefore, the nature and size of differences in scores between our study sample and the population norm could be appreciated directly. The results indicated that these injuries mainly affected the physical items of the SF-36 and that physical function was affected most, with the mean at 12 points below the population norm, just over $1 \mathrm{SD}(-37$ to +6$)$, but this did not reach statistical significance. The role physical and bodily pain scores were also lowered, but to a less degree. There is a large range of values for the eight items of the scale as shown by the median and interquartile range of the box plot (Fig. 2). We also compared the physical component score of those patients with an ISS $>20$ with those with a

\begin{tabular}{|c|c|c|c|c|}
\hline \multirow[b]{2}{*}{ Case } & \multicolumn{2}{|l|}{ IOWA } & \multicolumn{2}{|l|}{ SF-36 } \\
\hline & Knee & Ankle & PCS & MCS \\
\hline 1 & 99 & 100 & 55.2 & 61.8 \\
\hline 2 & 79 & 61 & 13.5 & 55.6 \\
\hline 3 & 96 & 87 & 504 & 56.8 \\
\hline 4 & $\mathrm{~N} / \mathrm{A}$ & $\mathrm{N} / \mathrm{A}$ & $\mathrm{N} / \mathrm{A}$ & N/A \\
\hline 5 & 94 & 90 & 42.4 & 47.4 \\
\hline 6 & 80 & 87 & 22.7 & 64.2 \\
\hline 7 & 92 & 99 & 57.0 & 52.0 \\
\hline 8 & 81 & 68 & 22.6 & 43.0 \\
\hline 9 & 74 & 83 & 30.3 & 43.0 \\
\hline 10 & 90 & 87 & 46.7 & 54.7 \\
\hline 11 & 89 & 83 & 40.4 & 63.7 \\
\hline 12 & $N / A^{*}$ & N/A & 25.8 & 43.7 \\
\hline 13 & 100 & 100 & 48.7 & 60.4 \\
\hline 14 & $\mathrm{~N} / \mathrm{A}$ & N/A & 43.1 & 56.5 \\
\hline 15 & 92 & 92 & 32.6 & 33.4 \\
\hline 16 & 96 & 94 & 46.0 & 65.3 \\
\hline 17 & 98 & 89 & 49.0 & 62.7 \\
\hline 18 & 90 & 83 & 40.3 & 29.7 \\
\hline 19 & 92 & 92 & N/A & $\mathrm{N} / \mathrm{A}$ \\
\hline 20 & 79 & 47 & 28.1 & 44.3 \\
\hline
\end{tabular}

lower ISS. The mean physical component score in the latter was higher (difference in means 4.1, SEM 6.6, two sample $t$-test, $0.53, \mathrm{p}=0.53$ ) suggesting a trend to a better component score in those with fewer injuries. However, this did not reach statistical significance because of the sample size. The mental health aspects were as good as those of the general population.

\section{Discussion}

The principal concerns arising from a segmental fracture of the tibial diaphysis relate to the biology and stability of the fracture. The high-energy fracture pattern damages inherent repair mechanisms to varying degrees. The presence of a compartment syndrome, reported in between $10 \%$ and $48 \%$ of fractures, can add to this. ${ }^{1,2}$ Some of the fractures are open, posing the additional threat of infection. Many authors have stressed the need for the chosen treatment to incur the least damage to the remaining biological reserve. ${ }^{1-3,6-13}$

Multilevel tibial fractures challenge the ability of standard implants to provide adequate stability at all levels. Whereas it can be argued that plate fixation may achieve this, the additional surgical injury to a compromised softtissue envelope, even with modern submuscular techniques, has to be balanced against the benefit of improved stability. The use of reamed intramedullary nails and locking screws can be successful if the fracture segments are neither too proximal nor too distal. However, reaming incurs a biological cost which affects the blood supply to the tibial cortex. ${ }^{14}$ Unreamed nails have been proposed as a compromise ${ }^{2}$ but, with either technique, the achievement of 

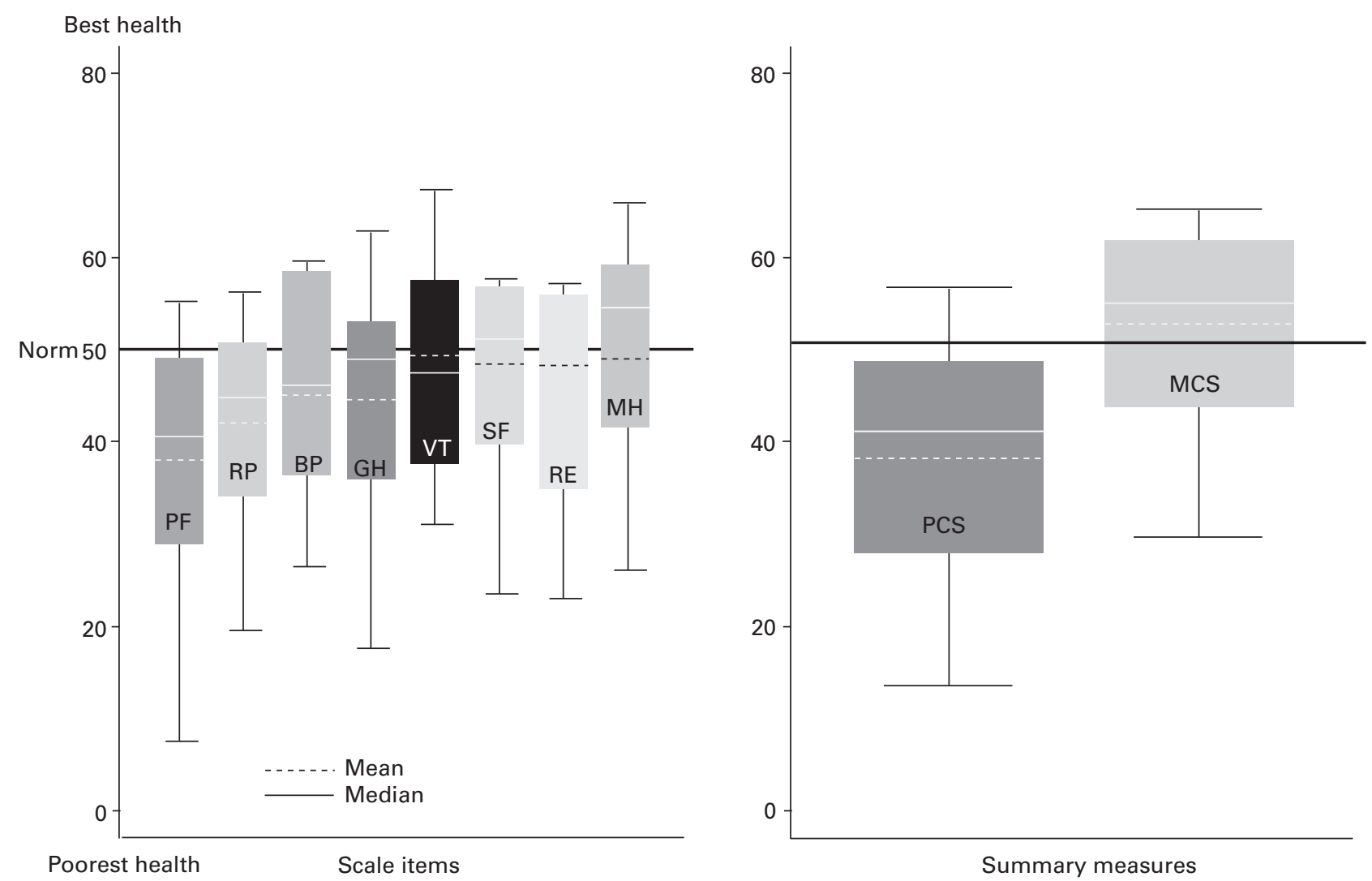

Fig. 2

Box-and-whisker plots showing norm-based scoring of the short-form 36 version 2 for United Kingdom population norms, 1998 (PF = Physical Functioning, $\mathrm{RP}=$ Role Physical, $\mathrm{BP}=$ Bodily Pain, $\mathrm{GH}=$ General Health, $\mathrm{VT}=$ Vitality, $\mathrm{SF}=$ Social Functioning, $\mathrm{RE}=$ Role Emotional, $\mathrm{MH}=\mathrm{Mental}$ Health, PCS $=$ Physical Component Score, MCS = Mental Component Score $)$.

multilevel stability can be difficult. Very short proximal segments are notoriously difficult to control, even with modern intramedullary nails and alterations to the technique of insertion have to be used to avoid malalignment. ${ }^{15}$

Conversely, treatment in an above-knee cast probably represents the least damaging method for the remaining vascularity of the tibial segments. If followed by functional bracing, it can be successful provided that the fractures are closed, have an acceptable degree of initial shortening $(<12 \mathrm{~mm})$ and that any angulation is corrected to within $7^{\circ} .{ }^{13}$ The mean time to healing is reported to be 15.3 weeks. ${ }^{13}$ However, this subgroup of segmental tibial fractures highlights the potential for conservative treatment if applied judiciously.

The final option for stabilisation of the fracture is external fixation. This method has the potential to leave a very small 'footprint' on the biology of the fracture and is probably equivalent to conservative methods if fixation pins are kept away from the fracture zones. Previous reports have documented its success for segmental tibial fractures, but have also stated problems with malunion, nonunion and deep infection. ${ }^{1,11}$ A possible explanation for some of the complications is the uniplanar stability provided by stan- dard external fixators and the inability to improve malalignment without return to the operating theatre.

Fracture contact (absence of a gap) has been emphasised by others, even when using other methods of stabilisation. ${ }^{7}$ Our series of 20 patients was treated using circular external fixators which were able to capture every segment of the fracture, offer circumferential control, allow post-application alterations in fracture alignment and contact, and leave a small biological 'footprint'. Also, since weight-bearing is an important stimulus to fracture healing, ${ }^{16,17}$ the stability provided enables the surgeon to allow weight-bearing, albeit partial, immediately after application, as long as the patient's other injuries allow it.

The mean time to union in our series was 21.7 weeks (12 to 31), which compares favourably with that in other reports ${ }^{2,3}$ of segmental fractures treated by different methods. The times to union with casts, braces and external fixators are likely to be different from those reported when internal fixation is used. The often quoted criterion of 'bridging callus across three of four cortices' has inherent bias in quantifying callus. No test of the strength of union is possible while the implant continues to support the healing fracture. While this may be irrelevant clinically, it highlights 
the difficulties of comparing times to union when internal or external devices are used.

Two other features of the time to union were observed. There was no significant difference in the healing time between proximal or distal levels of fracture. We believe that this may be because there was no significant difference in the size of the residual fracture gap. The other feature was the wide variation in the time to union (12.8 to 31 weeks). This reflected the heterogeneous nature of these fractures and the limitations of nomenclature and classification. Approximately $25 \%$ of the injuries were multisegmental.

Complications were encountered in four patients, two cases of nonunion at one level, one of wire-related infection and another of shortening of greater than $1 \mathrm{~cm}$ and residual valgus angulation of $8^{\circ}$. Only the first three required surgical intervention. The proportion of patients needing unscheduled secondary intervention was $15 \%$, which compared very favourable with the reported rates of $9.8 \%$ to $48 \%$. $^{2,3}$

The results of functional recovery and general health status must be interpreted in the light of the heterogeneous nature of these fractures and the presence of multiple injuries. This exerts a varying impact on the physical component scores, even though the IOWA ankle and knee scores appear to indicate a good to excellent return of joint function. It is of note that the Mental Component Score scored above the population norm.

This retrospective assessment of segmental tibial fractures has shown circular external fixation to be a reasonable method of treatment, which leaves a small biological 'footprint' and can achieve multilevel stability. There is a good mean time to union, a low rate of re-operations and good functional and general health-status outcome.
The author or one or more of the authors have received or will receive benefits for personal or professional use from a commercial party related directly or indirectly to the subject of this article.

\section{References}

1. Woll TS, Duwelius PJ. The segmental tibial fracture. Clin Orthop 1992;281:204-7.

2. Kakar S, Tornetta P 3rd. Segmental tibial fractures: a prospective evaluation. Clin Orthop 2007;460:196-201.

3. Giannoudis PV, Hinsche AF, Cohen A, et al. Segmental tibial fractures: an assessment of procedures in 27 cases. Injury 2003;34:756-62

4. No authors listed. Fracture and dislocation compendium: Orthopaedic Trauma Association Committee for Coding and Classification. J Orthop Trauma 1996; 10 Suppl1:VXI, 1-154.

5. Gustilo RB, Mendoza RM, Williams DN. Problems in the management of type III (severe) open fractures: a new classification of type III open fractures. J Trauma 1984:24:742-6

6. Fleming B, Paley D, Kristiansen T, Pope M. A biomechanical analysis of the llizarov external fixator. Clin Orthop 1989;241:95-105.

7. Yang L, Saleh M, Nayagam S. The effects of different wire and screw combinations on the stiffness of a hybrid external fixator. Proc Inst Mech Eng [H] 2000;214:669-76.

8. Davies R, Holt N, Nayagam S. The care of pin sites with external fixation. J Bone Joint Surg [Br] 2005;87-B:716-19.

9. Merchant TC, Dietz FR. Long-term follow-up after fractures of the tibial and fibular shafts. J Bone Joint Surg [Am] 1989;71-A:599-606.

10. Jenkinson C, Stewart-Brown S, Petersen S, Paice C. Assessment of the SF-36 version 2 in the United Kingdom. J Epidemiol Community Health 1999;53:46-50.

11. Rommens PM, Coosemans W, Broos PL. The difficult healing of segmental fractures of the tibial shaft. Arch Orthop Trauma Surg 1989;108:238-42.

12. Melis GC, Sotgiu F, Lepori M, Guido P. Intramedullary nailing in segmental tibial fractures. J Bone Joint Surg [Am] 1981;63-A:1310-18.

13. Sarmiento A, Latta LL. Functional treatment of closed segmental fractures of the tibia. Acta Chir Orthop Traumatol Cech 2008;75:325-31.

14. Hupel TM, Aksenov SA, Schemitsch EH. Effect of limited and standard reaming on cortical bone blood flow and early strength of union following segmental fracture. $J$ Orthop Trauma 1998;12:400-6.

15. Tornetta P 3rd, Collins E. Semiextended position of intramedullary nailing of the proximal tibia. Clin Orthop 1996;328:185-9.

16. Sarmiento A, Schaeffer JF, Beckerman L, Latta LL, Enis JE. Fracture healing in rat femora as affected by functional weight-bearing. J Bone Joint Surg [Am] 1977;59A:369-75.

17. Grundnes $\mathbf{0}$, Reikeras $\mathbf{0}$. Effect of physical activity on muscle and bone blood flow after fracture: exercise and tenotomy studies in rats. Acta Orthop Scand 1991;62:67-9. 